Accepted (peer-reviewed) version of article

It is authorized for self-archiving after an embargo period of up to 12 months.

Formatted by the author to enhance readability. 


\title{
Concepts and how they get that way
}

\author{
Karenleigh A. Overmann \\ Center for Cognitive Archaeology, \\ University of Colorado, Colorado Springs
}

Drawing on the material culture of the Ancient Near East as interpreted through Material Engagement Theory, the journey of how material number becomes a conceptual number is traced to address questions of how a particular material form might generate a concept and how concepts might ultimately encompass multiple material forms so that they include but are irreducible to all of them together. Material forms incorporated into the cognitive system affect the content and structure of concepts through their agency and affordances, the capabilities and constraints they provide as the material component of the extended, enactive mind. Material forms give concepts the tangibility that enables them to be literally grasped and manipulated. As they are distributed over multiple material forms, concepts effectively become independent of any of them, yielding the abstract irreducibility that makes a concept like number what it is. Finally, social aspects of material use-collaboration, ordinariness, and time-have important effects on the generation and distribution of concepts.

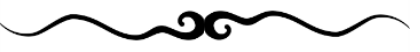

Even the dullest oaf can be made to understand that specie is not money, but a form of money. Money, then, whatever its real nature, reveals itself to us through form (Miller, 1980, p. 4).

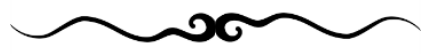

In an essay originally published in 1938 entitled "Money and how it gets that way," novelist Henry Miller tried to answer questions about what makes money money and how it gets to be what it is, focusing on the psychological entrapment of loving money, the so-called root of all evil and the Sisyphean treadmill of hedonic pursuit. He distinguished the concept money from the various forms it could assume: coins, banknotes, bottom line. Miller recognized that while money assumed varied and multiple material forms, as a concept it was irreducible to any of them. However, he sidestepped questions of how a concept might come to encompass multiple material forms to include but still be bigger than all of them together, and how a particular material form might become a concept in the first place, by writing, "Money is, and whatever form or shape it may assume it is never more nor less than money. To inquire therefore how it comes about that money has become what it now is is as idle as to inquire what makes evolution” (Miller 1980, p. 4). This left open the questions of how a material form might become a concept and how a concept might encompass multiple material forms, processes that can be illuminated by examining the material culture of the Ancient Near East through the lens of Material Engagement Theory.

Material Engagement Theory (Malafouris 2013) is archaeology that views human cognition as the systemic interaction of material structures, behaviors, and psychological process, finds evidence of the first two in the material record of the past, and interprets the evidence with an understanding of brain form and function drawn from cognitive science. As part of the 
cognitive system, materiality is recognized as having agency and semiotic value. What materiality is in terms of physical substance and form enables it to influence behavior and psychological processing; thus, change in the form of material artifacts over time can provide insight into changes in these domains. What materiality is and what people do with it gives it meaning, and together with agency this semiotic function influences conceptual content and structure. Such analysis cannot reveal what but rather how ancient people may have thought, providing potential insight into how extant peoples may think as well.

This cognitive inclusion is a different relationship with materiality than has traditionally been supposed, where mind and brain have often been conflated. The mind is synonymous with neural activity in the brain, and while materiality may stimulate this activity, it remains external to the mind. ${ }^{1}$ On this view, materiality is just stuff in the world that people think about. In contrast, Material Engagement Theory views cognition as more than activity in the brain. ${ }^{2}$ Specifically, it views cognition as extended and enactive. Extended means that materiality is a constitutive part of the mind, and enactive means that cognition is the interactivity of brains, bodies, and materiality. The theoretical nature of these definitions practically begs for a straightforward example of cognition that is extended and enactive, so one is offered here: reading, cognitive activity that only occurs when someone interacts with, for example, words printed on a page in a book. Reading and its productive counterpart, writing, are the interaction of psychological processes like objectrecognition and language, material forms like words on a page, and behaviors like handwriting that interface the two. In recognizing reading as the interactivity of psychological processes, behaviors, and material forms, the printed words must be acknowledged as a material form that interacts with psychological processes and behaviors (Overmann 2016a).

Of course, this material form was not invented suddenly in the form in which it currently exists. Rather, about 5,000 years ago in Mesopotamia, early writing had the form of pictograms and ideograms, ${ }^{3}$ "figurative and conventional drawings intended to have a communicative function” (Glassner 2000, p. 84). Over centuries and through the participation of generations of individuals, interaction with these material forms through the behaviors of writing and reading changed the psychological processing in the brains of the Mesopotamians; in turn, changes in psychological processing enabled changes in behaviors and the material form of writing (Overmann 2016a). For example, brains became trained to recognize pictograms and ideograms. Specifically, the fusiform gyrus of the temporal lobe, which has an evolutionary function for recognizing objects, became trained to recognize written objects as if they were physical objects, through combinations of their local and global features (Dehaene and Cohen 2007, 2011; McCandliss, Cohen, and Dehaene 2003), and associate them with the motor movements of handwriting and the meanings and sounds of language (Dehaene et al. 2010; Nakamura et al. 2012; Pegado, Nakamura, and Hannagan 2014). Feature recognition relaxed the need to preserve

\footnotetext{
${ }^{1}$ In actuality, this view is also relatively recent, as the treatment of neuroanatomist Franz Joseph Gall and his work in the early nineteenth century reveals: Between 1802 and 1817, the Church banned Gall's writing, had him expelled from jobs, cities, and countries, and reportedly excommunicated him for suggesting the brain had something to do with mental functioning (Gall 1835; Moscati 1832; Tovino 2007).

${ }^{2}$ While the brain is undeniably important to cognition, materiality is essential to psychological processes like perception, categorization, and abstraction. This means it is difficult to separate the internal and external aspects of cognition and leaves open the question of how much of the external world the brain reproduces internally (Hutto \& Myin 2013).

${ }^{3}$ Pictograms resembled what they meant (e.g., a picture of a head meant head because it looked like a head), while ideograms conveyed meaning through social agreement (e.g., a quartered circle meant sheep, not because it resembled a sheep in any way but because the Mesopotamians agreed that sheep is what the symbol meant).
} 
the original iconic form, so that sign form became less depictive, change that can be seen by examining so-called sign chronologies (i.e., comparisons of signs for particular words that show how their form changed over time). Greater abstractness of sign form, in turn, intensified the need for training to be able to produce and comprehend writing, and the need for training created communities of specialized practitioners (e.g., scribes and the literate elite).

It is not neurocentric to acknowledge that the brain undergoes neural reorganizations producing measurable changes in psychological processes realized through sustained exposure to specific behaviors and material forms, such as the ones just described as occurring in literacy. For this does not entail that such training effects are representational, the conception of material objects as passively internalized that contrasts with the active co-constitutivity and transformativity Malafouris (2010, 2015, 2016) advocates for mind and matter. Neither does it inflate the brain's importance in the cognitive system to recognize that enculturation and ontogenesis may significantly change it while simultaneously producing little-to-no change in material forms, as this is implicit in learning and using existing material culture (i.e., compared to altering or extending how it is used once proficiency has been acquired) and the very mechanism of cultural reproduction that transmits and distributes cognitive effort over space and time (Hutchins 1995). Nonetheless, it is also important to note that brains, bodies, and material forms do not merely interact but transform one another in an "ongoing relational transaction" wherein mind and matter are co-constitutively intertwined to a degree that they cannot be meaningfully separated (Malafouris 2015, p. 351; also see discussion of “metaplasticity” in Malafouris 2010, 2016).

Material things also acquire meaning through what people do with them, a process Malafouris (2013) calls enactive signification. Certainly, the materials used in writing acquired meaning as objects through the activity of making marks on clay. Today these things have names like tablet, stylus, and cuneiform script. The materials used for writing also influenced the form of writing, a property of materiality that Malafouris calls agency. For example, clay does not offer an ideal surface for drawing complex pictures with curved lines: The "wedge-to-wedge interaction[s]" (Cammarosano 2014, p. 79) implicit in making close, complex marks on a small clay surface typically yield a confusion of indistinguishable furrows, influencing pictograms and ideograms toward simplicity and linearity. There were also psychological and physiological aspects to change in the material form of writing, as for example the abilities to identify and distinguish characters visually influenced both the form of writing and the movements needed to produce them (Overmann 2016a).

In what follows, the material culture of the Ancient Near East, particularly the technologies used for counting in its number system, is interpreted through Material Engagement Theory to address Miller's unanswered questions. Particular emphasis will be placed on how behavioralmaterial-psychological interactivity generates concepts like number from material forms; how material agency influences behavior, psychological processing, and conceptual content and structure, and the effect of distributing concepts over multiple material forms. The criticality of the social nexus to the sustained use of materiality as a collaborative medium will also be examined, but as social aspects of cognition are often addressed, the focus here will remain on the material.

\section{How a material form becomes a concept}

To answer the first of Miller's open questions, material forms become concepts through enactive signification, as the material forms of clay and reeds took on Sumerian names equivalent 
to our words for tablet and stylus through the activity of using them to make marks that would ultimately be called the cuneiform script. Mesopotamian numbers illustrate an important aspect of this process, as they involve manipulation of the material form into novel stimuli. However, what a concept is, and then what a number is as a concept, must first be defined.

A concept is "a unit of structured thought” that is associated with an agent but independent of the agent's context, and which is both revisable and capable of generating new concepts through processes like combination and decomposition (Parthemore 2013, p. 168). Concepts can be analyzed as blends of (internal) mental and (external) material inputs like knowledge (mental), features (physical), and capacities (both) (Fauconnier 1997; Malafouris 2013). Blending occurs when interactions between the mental and the material transform experience to create meaning (Di Paolo, Rohde, and De Jaegher 2010). A blend "inherits partial structure from the input spaces and has emergent structure of its own" (Fauconnier 1997, p. 149-151, emphasis original). Material forms anchor and stabilize the blend, and their "perceived relationships ... are taken as proxies (consciously or unconsciously) for relationships among conceptual elements" (Hutchins 2005, p. 1562). These functions suggest the importance of manipulating material forms into novel stimuli. Material forms also augment what the brain provides (e.g., mental capabilities and conceptual content that augment what is observed with knowledge, inferences, and conjectures) and help overcome limitations in psychological functions like working memory and attention.

A number, essentially, is the idea of quantity shared by sets of objects (Russell 1910, 1920). ${ }^{4}$ This makes numbers uniquely bound to the material forms that instantiate them as concepts. Initially, there will not be a word to express the concept of shared quantity. Such alinguistic counting remains quite familiar in the modern rosary, where beads are matched to prayers without the need to enumerate either. Lacking words to express the concept, one of the sets is then used to represent it. The so-called reference set is often the fingers, for reasons that include their neurological integration with the quantity sense, handy availability as a material device, and role in bridging psychological, behavioral, and material aspects of object manipulation (Overmann 2014, 2016b, 2016d). Use of the fingers (or some other material device) makes the concept of number tangible, expressible, and shareable (Coolidge and Overmann 2012; Malafouris 2010) and starts the process whereby number - a culturally constructed concept-is realized from the sense of quantity shared with other species (Núñez 2017). Simply, then, a concept of number is generated when materiality is manipulated through strategies like one-to-one correspondence that allow the quantity of two sets of objects to be compared (e.g., as many prayers as rosary beads), a process that also imparts the stable order

\footnotetext{
${ }^{4}$ Russell's definition of number as cardinality shared by sets of objects implies that such concepts are realized by comparing sets for their cardinality, and indeed, such comparisons are well documented in the ethnographic literature as behaviors like pairing and one-to-one correspondence. In pairing, small sets of objects are compared; comparing two pairs affords an opportunity to appreciate their shared quantity (i.e., "two"), while comparing a pair with a single object affords an opportunity to appreciate their dissimilar quantity (i.e., "two" and "one”). In one-toone correspondence, larger sets are iteratively matched, element by element, until all elements have been matched once with none remaining. Neither pairing nor one-to-one correspondence need presuppose concepts of or words for numbers because "it is simpler logically to find out whether two collections have the same number of terms than it is to define what that number is" (Russell 1920, p. 15). Certainly, "although language transforms and extends our conceptual abilities, it does not make them possible in the first place” (Parthemore 2013, p. 169). However, through mechanisms like enactive signification and pattern recognition, behaviors that manipulate objects into arrangements where their shared (or dissimilar) quantity can be recognized have the potential to generate such concepts.
} 
(Gelman and Gallistel 1978) that is "essential to most of [numbers'] mathematical properties" (Russell 1920, p. 29; also see Zahidi and Myin 2016). The brain recognizes a pattern ${ }^{5}$ (i.e., the shared quantity) and ignores extraneous information (e.g., like the fact that, aside from their quantity, beads and prayers have very few properties in common), activities at which the human brain is superb. Then one of the material forms is used to express that recognition, giving it subsequent opportunity for being named in language, shared with other people, and so on (Coolidge and Overmann 2012). Once the concept takes the form of material culture and language, it becomes part of social knowledge. Material culture and language then intermediate what a society knows and an individual learns (Haas 1996).

The recognition of shared quantity, however, is not the modern concept of number, which has been elaborated over millennia to include ordering by increasing magnitude, specifiable relations between numbers, and operations that manipulate the relations between numbers. Material culture has a lot to do with this elaboration and the resultant concepts, processes for which the counting technologies of the Ancient Near East hold relevant insight. Combined archaeological, textual, and linguistic evidence suggests that at least four technologies-fingers, tallies, tokens, and numerical notations - were used in the Ancient Near East to represent and manipulate numbers over a span of about 30,000 years (Overmann 2016b). Unambiguous numbers appeared relatively late in the sequence, in the form of numerical impressions made with tokens (or similarly shaped objects) in the late fourth millennium BCE (Schmandt-Besserat 1992). Then a stylus was used to produce shapes and sizes similar to those of the tokens and impressions (Nissen, Damerow, and Englund 1993). Writing by hand with a stylus influenced numerical notations toward greater concision, at least partly as a result of the psychological and behavioral changes that attended writing and reading, as mentioned previously (Overmann 2016a).

Objects purported to have been numerical tokens have been found as early as the tenth millennium BCE (Moore 2000) and as late as the first (MacGinnis, Monroe, Wicke, and Matney 2014), but they predominate in and are thus particularly associated with the Neolithic (Schmandt-Besserat 1992). Various issues in determining whether tokens were used as numerical counters have been identified (e.g., Englund 1998; Friberg 1994; Zimansky 1993), with the result that the identifications that are most secure are found in the late fourth millennium BCE, when there are clear correspondences between the conventions of shape and size used in tokens and numerical impressions (Friberg 1994; Høyrup 1994). These conventions of shape and size encoded two things: first, the type of commodity the tokens enumerated, and second, bundling relations between tokens (i.e., in which, for example, between two and twelve tokens of one type were equal to one token of another type) (Nissen et al. 1993). While the correspondences allow their identification with numerical meaning, tokens were simply an accounting system, with no intrinsic value. Like modern grocery receipts, once their information was no longer useful they were discarded as rubbish (this is where archaeologists tend to find them, context wherein any presumed numerical use is often unclear).

As a way of recording numerical information, tokens had two exponential dimensions (Chrisomalis 2010). One dimension consisted of ordinal counting, the other of bundling relations. This arrangement is used in modern currency: For example, U.S. currency includes a unit (e.g., the dollar), unit multiples (e.g., five-, ten-, and twenty-dollar bills), and unit fractions (e.g., quarters, dimes, nickels, and pennies). Tokens and early written notations too were systems

\footnotetext{
${ }^{5}$ Patterns are so important in numbers that mathematics has even been called the science of patterns (Devlin 2003).
} 
with a unit and multiples, and some of the systems also included fractions (but again, unlike money, the units, multiples, and fractions had no intrinsic value of their own). The multiples and fractions were related to the unit and each other both metrologically (i.e., like four quarts equal a gallon today) and numerically (i.e., as four of one kind of token equaled one token of another kind). Two exponential dimensions gave tokens a level of complexity that implies one or more single-dimension precursor technologies. In fact, there is evidence of two such precursors, tallies and fingers. Worked bones that may have been used as tallies have been found in multiple sites in the Levant throughout the Late Upper Paleolithic (e.g., Reese 2002; Tixier 1974). While similar artifacts are rare in Mesopotamia, this is likely the result of poor preservation related to climatic conditions (Coinman 1996). Certainly, the practice appears to have persisted, as there is a poem from the second millennium BCE entitled "The debate between grain and sheep" that translates as, "Every night your count is made and your tally-stick put into the ground, so your herdsman can tell people how many ewes there are and how many young lambs, and how many goats and how many young kids” (ETCSL 2005). Tallies are also attested archaeologically in the first millennium BCE (Henkelman and Folmer 2016).

Use of the fingers for counting is suggested by the presence of characteristic cycles of five, ten, and twenty in ancient numbers. Cross-culturally, the use of the hand as a material structure for counting imposes characteristics like the patterning of ten-ness known as decimal or base 10 . One hand yields quinary (base 5); both hands and the toes yield vigesimal (base 20). Such characteristics are found in a majority of contemporary number systems (Comrie 2013; Greenberg 1978; Menninger 1992), and the ancient number systems of Mesopotamia as well. The Akkadian and Elamite number systems were decimal, while in Sumerian, the words for the numbers six through nine were "five plus" compounds (e.g., six was "five plus one"), and numbers for units of 10 were multiples of ten or twenty (e.g., thirty was "three tens," and forty was "two twenties”) (Blažek 1999; Dombrowski and Dombrowski 1991; Englund 2004; Nissen et al. 1993; Wilcke 2005). While patterning by fives, tens, and twenties has long been understood as finger-counting (e.g., Diakonoff 1983), the evidence cannot establish an absolute chronology for when the Mesopotamians began counting on their fingers. However, because finger-counting characterizes extant number systems across the full range of elaboration, it is reasonable to conjecture that finger-counting would have done so in the ancient number systems as well, arguably positioning it as the earliest technology used. Notably, the Sumerian, Akkadian, and Elamite languages were unrelated: Sumerian and Elamite were linguistic isolates (i.e., they are not related to any other known language, including each other), while Akkadian was a Semitic language. This circumstance suggests that Mesopotamia was home to at least three separate numerical traditions. ${ }^{6}$ Not only were these numerical traditions in contact with one another, they each had small but significant differences (like their patterning) that would have opened up elaborative opportunities through the contrasts they provided.

\footnotetext{
${ }^{6}$ There was a possible fourth indigenous counting system, ternal counting, that has been variously explained as a women's language (an emesal or dialect spoken chiefly by women) or a literary convention (Whittaker 2002). However, ternal counting is associated with topics, archiving, and training found in scribal and priestly contexts (i.e., predominantly or exclusively male) (Lambert 1969), calling into question its identification as a woman's dialect; it also seems overly specific to have been invented for purely literary purposes. A plausible alternative explanation is that it might have been the counting system of a minority culture.
} 


\section{How a concept becomes distributed over multiple material forms}

Material agency and semiotic function influence the conceptual content and structure of numbers. For example, a tally accumulates fairly easily, as notches are added to an artifact. Further, notches are related to each other by proximity, so the relations between notches (and numbers) are relatively limited: plus-one, more than, less than, and not equal to. And once they have been made, notches are relatively difficult to move or remove. Thus, the concept of number most likely to be associated with a tally is an ordinal sequence, numbers that are arranged in order of increasing magnitude. Given a material structure like a tally that supports accumulation, an ordinal sequence in language, and relatively few relations between numbers, an emergent requirement for subtraction will most likely be handled by reversing the ordinal sequence from the top count on the artifact. For example, if the task is to subtract nine from fifteen, first fifteen notches will be counted up, and then nine notches will be counted down from the fifteenth notch. In fact this method has been documented in the body-counting system of the Oksapmin people of Papua New Guinea (i.e., whose material structure, like a tally, supports accumulation, an ordinal sequence of number-words, and relatively few relations between numbers), when posed subtraction tasks by a Western observer (Saxe 2012).

Because of the close relationship between what a material can and cannot do (i.e., its agency) and numerical structure, the concept number acquires different structural properties as new material forms are incorporated into the cognitive system for number. This is because different material forms provide different affordances, or capabilities and constraints (see Table 1). ${ }^{7}$ Fingers, for example, are neurologically connected to quantity perception (e.g., Roux, Boetto, Sacko, Chollet, and Trémoulet 2003). ${ }^{8}$ Because these psychological processes interact at the neural level with others (e.g., working memory, attention, and movement automaticity), the use of the fingers as a material technology influences numbers toward linearity and stable order (Gelman and Gallistel 1978). However, fingers also have a relatively limited capacity and duration: They generally count to five per hand, and their use in recording numerical information inhibits alternative use of the hand. Given social pressure for enumeration to greater numbers for longer durations, these limitations will motivate the incorporation of a technology with greater capacity and persistence (e.g., tallies, knotted strings).

Technologies like tallies both reflect and impose linearity and stable order. That tallies reflect qualities like linearity suggests that their selection as a new material form was based at least in part on their similarities with fingers; that they impose qualities like linearity is a function of what they are as material form. Tallies not only accumulate to higher quantities and for longer durations, they also represent the transition to material culture, which not only facilitates the distribution of cognitive effort (Hutchins 1995) but makes available a collaborative

\footnotetext{
${ }^{7}$ An affordance is a relation between what an organism (or agent) is capable of and what its environment enables it to do; originally from Gibson's $(1977,1979)$ ecological psychology, affordances are identified by Malafouris (2013) as a mechanism through which materiality exerts agency.

${ }^{8}$ Linguistic evidence shows that Mesopotamian peoples had the same perceptual experience of quantity that extant peoples do (Overmann 2015, 2016b). This is entirely predictable, given that the ability to appreciate quantity is found in nonhuman primates, mammals generally, birds, amphibians, fish, and perhaps even insects, phylogenetic distribution that suggests that the ability would undoubtedly have been shared by the species and peoples ancestral to extant humans. However, it is important to distinguish the perceptual experience of quantity from the concept of number, which is culturally constructed (Núñez 2017) through material engagement (Overmann 2016c).
} 


\section{Table 1. Affordances and limitations in artifacts used as material counting technologies in the Ancient Near East.}

\begin{tabular}{|c|c|c|}
\hline Artifact & Affordances & Limitations \\
\hline Fingers & $\begin{array}{l}\text { - Neurologically integrated with quantity perception } \\
\text { - Psychological-behavioral-material bridge } \\
\text { - Available; manipulate the objects being counted } \\
\text { - Linearity; stable order }\end{array}$ & $\begin{array}{l}\text { - } \quad \text { Limited capacity; ephemeral } \\
\text { - } \quad \text { Commodity unspecified }\end{array}$ \\
\hline Tallies & $\begin{array}{l}\text { - Linearity; stable order } \\
\text { - Accumulation } \\
\text { - } \quad \text { More capacity; persistent }\end{array}$ & $\begin{array}{l}\text { - } \quad \text { Commodity unspecified } \\
\text { difficult to discriminate visually; not } \\
\text { manipulable; one-dimensional }\end{array}$ \\
\hline Tokens & $\begin{array}{l}\text { - Linearity; stable order (imposed: not implicit in } \\
\text { the form) } \\
\text { - Accumulation; greater capacity; persistent } \\
\text { - } \quad \text { Commodity encoded } \\
\text { - } \quad \text { Grouped (more discriminable); manipulable } \\
\text { (operations; relations); two-dimensional }\end{array}$ & $\begin{array}{l}\text { - Loose (imposing the need for } \\
\text { containment); not concise; } \\
\text { multivalent }\end{array}$ \\
\hline Notations & $\begin{array}{l}\text { - Linearity; stable order (imposed) } \\
\text { - } \quad \text { Many operations; greater capacity; persistent } \\
\text { - } \quad \text { Commodity specified apart from number } \\
\text { - } \text { Integrity of form; concise; monovalent } \\
\text { - Handwritten (fusiform gyrus becomes trained; } \\
\text { improved hand-eye coordination; improved } \\
\text { character recognition and recall); } \\
\text { - } \quad \text { Whonceptualization as objects } \\
\text { - Table-part relations (with tokens) } \\
\text { - } \quad \text { Greater complexity of calculation }\end{array}$ & $\begin{array}{l}\text { - Fixed (must calculate with tokens or } \\
\text { manipulate relations between } \\
\text { numbers with new algorithms) }\end{array}$ \\
\hline
\end{tabular}

Notes. The material technologies used for counting in the Ancient Near East have been placed in chronological order and analyzed in terms of their affordances and limitations, and how these might have been a factor in the selection of new material technologies. New technologies appear to have been selected on the basis of affordances they shared with a previous technology (e.g., the linearity and stable order shared by fingers and tallies), and the selection of new technologies appear to have been motivated by limitations in a previous technology (e.g., as tallies provide capacity and persistence that finger lack). Some structural characteristics appear to have persisted across change in material technologies (e.g., tokens, at least at the point where they were impressed in clay surfaces, shared linearity and stable order that was imposed rather than implicit in the tokens themselves). However, it is likely that older technologies were retained rather than replaced, as is the case in contemporary societies, where multiple material forms for representing and manipulating numbers are used concurrently.

medium for using and sharing numbers (something that bodies are not, as they are crossculturally subject to restrictions on public touching and display). Tallies, however, provide limited manipulability and in accumulating to higher quantities become increasingly subject to increased visual indiscriminability when there are more than three or four notches, a function of the perceptual experience of quantity. Given social requirements, these limitations will motivate 
the adoption of a material form with manipulability and grouping, like tokens ${ }^{9}$ ). For their part, tokens represent the emergence of numeration based on manipulation and knowledge of numerical relations, and written notations enable numbers to become conceptualized as entities through their concision and the effects of handwriting.

Just as what materials can and cannot do influence numerical content, organization, and structure, so do what material forms are and how they are engaged. As concepts of discrete quantity, numbers are initially equivalences that match fingers and objects (i.e., five objects are as many as the fingers on one hand). With tallies, numbers become collections in which one notch means one object, and the source of productive grouping once provided by fingers is no longer apparent. As tokens are incorporated, numbers are collections that are related to each other, in addition to the objects they enumerate, and the source of their linearity and stable order is no longer apparent. Finally, numbers become conceptualized as objects or entities in their own right through mechanisms like handwriting effects. ${ }^{10}$ They become related to other numbers as their concision enables them to record large volumes of relational data (e.g., tables of multiplication or reciprocals), which is learned through the processes of recreating the data (as scribes were required to do in Mesopotamia as a part of their training). They become at last the concepts of "pure quantity" whose "abstract, non-empirical nature" has begged explanation for millennia (Stewart 2014, p. 8). However, the source of the manipulability needed to develop relations and algorithms is no longer apparent in the fixed form of the written numeral. Attributes like linearity, stable order, productive grouping, and manipulability remain part of the concepts, but they may no longer be implicit in the material forms used to represent the concepts. These phenomena will be called, respectively, conceptual change and structural persistence.

Material structure persists for several reasons. One is that the material component, considered across space and time, is really a patchwork out of which new forms can emerge and in which older and newer forms often coexist. There are neurological reasons for the persistence of structure, like the neural interaction that underlies and perpetuates finger-counting across and despite often-significant differences of elaboration in the numerical traditions of distinct cultural groups. Learning and practice, which represent structured interactions with materiality, are also social behaviors that transmit such knowledge between individuals and generations. And, when numbers are entities with linear order, productive grouping, and manipulable relations, material structure is implicit in the concepts themselves. Most importantly, what material form is capable of as a physical substance enables, limits, and structures what people can do with it. The

\footnotetext{
${ }^{9}$ The numerical impressions of the mid-fourth millennium BCE were organized by increasing magnitude, implying that the Neolithic tokens to which their sizes and shapes corresponded most likely were as well. This organization further implies that the surfaces on which tokens were manipulated may have been organized in some fashion, perhaps temporarily and as needed by drawing lines in dust or sand, or more formally and repeatably through the use of counting boards. The word abacus may have originated in the West Semitic word for dust (Semitic Roots 2017), and Akkadian was a related (East Semitic) language. Further, the Sumerian signs for words like counting had forms that were vaguely abacus-like, and abaci (and before them, counting boards with pebbles or calculi) were known in many parts of the ancient world (Ifrah 2000). These circumstances have led authors like Ifrah (1981, 2000) to infer that the abacus was used in Mesopotamia. Certainly, the abacus provides both visual discriminability and manipulability. However, the use of an abacus in Mesopotamia has not been established through archaeological or textual means (e.g., findings of abaci or their depictions, analogous to the first millennium BC Salamis counting board and the Dareios vase; mentions of abaci, counting boards, lines in the dust, etc., or descriptions of methods used to organize the surfaces used for manipulating tokens).

${ }^{10}$ Whether numbers are conceived as collections or entities is linguistically distinguished: In collections, two and two are four, while with entities, two plus two is four (Gowers 2008).
} 
structure of older material forms also influences the structuring potential of newer forms because materiality conditions people to things working in certain ways, and this narrows the range of possible behavioral outcomes.

As the Ancient Near Eastern number system elaborated by incorporating additional material technologies, there were two major trends. One is that numerical representations became increasingly concise. For example, consider how the number "75" would be represented with fingers, tallies, tokens, and numerical notations. It takes fewer cuneiform numbers than tokens, fewer tokens than tally notches, and fewer tally notches than fingers. Both hands of eight people would be required, but a single tally stick would display the same amount with 75 notches. Reducing the number required even further, “75” would have been represented by 12 tokens (i.e., seven of the tens token and five of the unit tokens). Most concise of all were the sexagesimal (base 60) numerical notations written in cuneiform script, which would require only three signs: one 60-symbol, one 10-symbol, and one five-symbol. This concision was an important factor in being able to appreciate numbers not just as entities in their own right but as parts of a numerical system, as concision enabled the relations between numbers to be displayed, learned, and incorporated. These relations are critical to what numbers are, just like notes are to music and sounds are to language (Plato 1892).

The other trend in the elaboration of Ancient Near Eastern numbers was distribution. As new material forms were incorporated, the concept number was distributed across them, while retaining structural and content characteristics acquired from previous technologies. This made the concept effectively independent of any particular material form, yielding the "abstractness" that makes things like numbers and money what they are: concepts that encompass multiple material forms, but are bigger still than all of them put together. Distribution is implicit in the persistence of older forms, not only in the structure and capabilities they provide, but perhaps in their actual use as well. For example, Western peoples today still count with their fingers, make tally marks ( $($ fl), and use coins and banknotes, along with writing numbers on paper and poking them into computers and calculators, and the Western concept of number encompasses all these various ways of representing them, as well as the things they are applied to-like time, distance, speed, cost, and temperature. The presence of tallies and tokens, thousands of years after their first appearance in the archaeological record, suggests that Mesopotamian numbers were similarly distributed. When numbers are materially distributed, they structure how the world is experienced and engaged. In being distributed across multiple forms of materiality, numbers also become independent of any one particular form, an attribute that helps them function abstractly, and which makes the material component of cognition transparent to human cognition.

\section{Materiality as collaborative medium}

There is an important social aspect to cultural systems like numeracy and literacy, not yet discussed: materiality is used as a collaborative medium, and this has important implications for how material forms generate concepts and concepts become distributed over multiple material forms. As a collaborative medium, materiality teaches each member of a group or society more or less the same thing in more or less the same way. When an individual performs a task, imparting it to someone else is done through observation and/or language, which loses the fidelity of the sensorimotor experience involved in task performance. However, when two individuals perform the same task, sensorimotor experience is in a sense shared, enriching a shared understanding. In 
this way, collaborative interactivity with materiality becomes part of the social fabric, different than but as important as language and observation. Collaborative interaction with the forms of material culture thus enables cooperative action and fosters shared understanding. Over generations of collaborative participation, interaction with material forms influences change in behavior, psychological processing, and conceptual content, influencing in turn change in material form. This iterative process makes material forms increasingly capable of eliciting particular behavioral and psychological responses as they intermediate social knowledge and individual learning. And material forms embody and make available the change accumulated by past generations, help recreate the change in newly enculturated individuals, and afford possibilities for future change.

The collaborative use of materiality is critical to material forms becoming concepts and concepts becoming distributed over multiple material forms, for several reasons. First, the collaborative use of numbers and writing supports their basic function, the representation and communication of concepts. It is certainly possible for an individual to be numerate or literate in an otherwise anumerate or non-literate population. However, in such a case numeracy and literacy would amount to a personal code, meaningless to all but the individual who had learned it, and it would fail to perform its basic function of expressing and exchanging ideas. ${ }^{11}$ Second, because they are collaborative in nature, numeracy and literacy involve similar neural reorganization across multiple individuals, change at the level of the group that can only be realized through collective participation in the same behavioral-material-psychological interactivity. Third, collaborative use by multiple individuals ensures that tools fit the average user, while becoming increasingly adapted to their purpose. When multiple individuals participate in the same task, each brings to it psychological and physiological capabilities and behaviors that differ within the range of human variation. Collaboration across such variation yields a regression-to-the-mean effect that keeps cultural systems like numbers and writing aligned to average capabilities and behaviors, while at the same time allowing the material form of the systems to change. And because they are fit to the average user, numbers and writing remain widely accessible, ${ }^{12}$ despite the ways in which they change over time. This too ensures they retain their representational and communicative function.

Collaborative use of materiality also helps spread newly realized concepts and puts the realization of complex cultural systems within the grasp of any society that engages in the requisite behaviors and supports their sustainment as the behaviors become more specialized. Newly realized concepts spread when one individual does something like impress a set of tokens on the outside of their clay container before enclosing them, ${ }^{13}$ and another thinks it is a good idea and repeats it, giving the behavior, material form, and associated concepts and knowledge a chance to percolate through a community and throughout a society. The idea of a moment in

\footnotetext{
11 Numbers are translinguistic in their apprehension and communicability (this is a function of how materiality instantiates quantity, and possibly because the appreciation of quantity is an innate perceptual sense that humans share with other species), so numeracy in that sense is less limitable to an individual. For literacy, the distinction is being drawn with regards to a modern script, which cannot be read without the requisite training and practice; writing systems that involve pictograms and ideograms (e.g., early Mesopotamian writing) require less training and practice, so in that sense they would be less limitable to an individual as well.

12 Accessibility means average people can acquire and participate in basic numeracy and literacy, not necessarily that everyone can perform advanced mathematics or engage the range of thought opened up by literacy.

${ }^{13}$ This is the specific technological change thought to have led to the separation of the representation of quantity and commodity that opened up the possibility of their subsequent elaboration as numbers and writing (Malafouris 2010; Schmandt-Besserat 1992).
} 
time when one individual's action is repeated by another suggests that numbers and writing are invented or created, and indeed, such terms are often used in discussing their origins (e.g., Glassner 2000; Ifrah 2000; Shendge 1983). Invention and creation, however, are inapt terms, as it is extremely unlikely that a single person or even an entire society could ingeniously devise a cultural system as complex as literacy or numeracy. For one reason, in at least their initial expression, writing and numbers give no clue to the ways in which they have the potential to reorganize brains, behaviors, and conceptual content and structure; for another, change is often imperceptible over the multigenerational spans of time involved. Thus, there are no teleological goals or aha! moments to spark a realization of what is needed and must follow in achieving such directions and destinations. The alternative is the idea that cultural systems develop when ordinary people make mundane use of materiality as a collaborative medium over long spans of time. The neurofunctional reorganizations involved in numeracy and literacy are merely unanticipated outcomes of these mundane behavioral-material-psychological interactions.

When numeracy and literacy are analyzed as cognitive change emerging from the interactivity between brains, bodies, and materiality within a nexus that includes social support and sustainment of the requisite collaborative behaviors with material forms, at least partial answers to Miller's open questions can be formed. However, these partial answers raise more issues than they help settle: The collaborative use of material forms of numbers and writing are implicit to the development of numeracy and literacy, but is this the same for other domains of human life? In other words, does an object like a chair have the same potential to realize behavioral and psychological change? And if not, what is it about chairs or other forms of material culture that differentiate them from numbers and writing in this regard? Are numeracy and literacy unique in the ways their material forms help generate and distribute concepts? Representation by means of material forms makes numerical concepts and relations accessible because it enhances the ability to visualize them and helps bypass psychological constraints in functions like working memory; how similar are writing and language to numerals and numbers in this regard? And are other domains of human thought influenced in terms of content and structure by materiality to the same extent as they are in numbers in particular?

Addressing such questions will be difficult, especially when some that should be asked are unknown, and others cannot yet be formed (i.e., by no means are the few identified above an exhaustive list). Conceivably, however, one way forward involves reconceptualizing material culture as a constitutive part of the human cognitive system with agency and semiotic value, and then seeing what analytic insights the approach of Material Engagement Theory may afford (Malafouris 2013).

\section{Acknowledgements}

I thank two anonymous reviewers for their close reading of and insightful comments on the draft, which led to its improvement. Admittedly, I resisted their recommendations for greater inclusion of the social aspects of numerical cognition in this work. As an archaeologist, where many researchers in numerical cognition foreground social transactions and mention the material as an ancillary matter, I reverse this order specifically and intentionally to focus on how the material structures used for counting inform the content, structure, and organization of numerical concepts over time, as well as the use of materiality as a collaborative medium for change on the level of society. The extent to which this is a fault is entirely mine. I also thank Lambros Malafouris, whose work significantly influences my own, for the opportunity to submit a paper for this special issue. 
Correspondence concerning this article should be addressed to Karenleigh A. Overmann, Center for Cognitive Archaeology, Department of Anthropology, University of Colorado, Colorado Springs, 1420 Austin Bluffs Pkwy, Colorado Springs, CO 80918, USA. Email: karenleigh.overmann@keble.oxon.org.

\section{References}

Blažek, V. (1999). Numerals: Comparative etymological analyses and their implications: Saharan, Nubian, Egyptian, Berber, Kartvelian, Uralic, Altaic and Indo-European languages. Brno, Czech Republic: Masarykova Univerzita.

Cammarosano, M. (2014). The cuneiform stylus. Mesopotamia, XLIX, 53-90.

Chrisomalis, S. (2010). Numerical notation: A comparative history. Cambridge: Cambridge University Press.

Coinman, N. R. (1996). Worked bone in the Levantine Upper Paleolithic: Rare examples from the Wadi al-Hasa, West-Central Jordan. Paléorient, 22(2), 113-121.

Comrie, B. (2013). Numeral bases. In M. S. Dryer \& M. Haspelmath (Eds.), World atlas of language structures online. Leipzig: Max Planck Institute for Evolutionary Anthropology. http://wals.info/chapter/131. Accessed 3 August 2017.

Coolidge, F. L., \& Overmann, K. A. (2012). Numerosity, abstraction, and the emergence of symbolic thinking. Current Anthropology, 53(2), 204-225.

Dehaene, S., \& Cohen, L. (2007). Cultural recycling of cortical maps. Neuron, 56(2), 384-398.

Dehaene, S., \& Cohen, L. (2011). The unique role of the visual word form area in reading. Trends in Cognitive Sciences, 15(6), 254-262.

Dehaene, S., Pegado, F., Braga, L. W., Ventura, P., Filho, G. N., Jobert, A., et al. (2010). How learning to read changes the cortical networks for vision and language. Science, 330(6009), 1359-1364.

Devlin, K. (2003). Mathematics: The science of patterns: The search for order in life, mind and the universe. New York: Henry Holt and Company.

Diakonoff, I. M. (1983). Some reflections on numerals in Sumerian: Towards a history of mathematical speculation. Journal of the American Oriental Society, 103(1), 84-92.

Di Paolo, E. A., Rohde, M., \& De Jaegher, H. (2010). Horizons for the enactive mind: Values, social interaction, and play. In J. Stewart, O. Gapenne, \& E. A. di Paolo (Eds.), Enaction: Toward a new paradigm for cognitive science (pp. 33-87). Cambridge, MA: MIT Press.

Dombrowski, F. A., \& Dombrowski, B. W. W. (1991). Numerals and numeral systems in the HamitoSemitic and other language groups. In A. S. Kaye (Ed.), Semitic studies in honor of Wolf Leslau on the occasion of his eighty-fifth birthday (Vol. I, pp. 340-381). Wiesbaden: Otto Harrassowitz.

Electronic Text Corpus of Sumerian Literature (ETCSL). (2005). Translation of "The debate between grain and sheep" (lines 130-133). Oriental Institute, University of Oxford. http://etcsl.orinst.ox.ac.uk. Accessed 16 June 2016.

Englund, R. K. (1998). Review: Denise Schmandt-Besserat, How writing came about. Written Language and Literacy, 1, 257-261.

Englund, R. K. (2004). The state of decipherment of proto-Elamite. In S. D. Houston (Ed.), The first writing: Script invention as history and process (pp. 100-149). Cambridge: Cambridge University Press.

Fauconnier, G. (1997). Mappings in thought and language. Cambridge: Cambridge University Press.

Friberg, J. (1994). Preliterate counting and accounting in the Middle East: A constructively critical review 
of Schmandt-Besserat's Before writing. Orientalistische Literaturzeitung, 89(5-6), 477-489.

Gall, F. J. (1835). On the functions of the brain and of each of its parts: With observations of the possibility of determining the instincts, propensities, and talents, or the moral and intellectual dispositions of men and animals, by the configuration of the brain and head (Vol. 1). (W. Lewis Jr., Trans.). Boston, MA: Marsh, Capen and Lyon.

Gelman, R., \& Gallistel, C. R. (1978). The child's understanding of number. Cambridge, MA: The President and Fellows of Harvard College.

Gibson, J. J. (1977). The theory of affordances. In Perceiving, acting, and knowing: Toward an ecological psychology (pp. 127-143). Hillsdale, NJ: Lawrence Erlbaum.

Gibson, J. J. (1979). The ecological approach to visual perception. Boston, MA: Houghton Mifflin.

Glassner, J.-J. (2000). The invention of cuneiform: Writing in Sumer. (Z. Bahrani \& M. Van de Mieroop, Trans.). Baltimore, MD: Johns Hopkins University Press.

Gowers, T. (Ed.). (2008). The Princeton companion to mathematics. Princeton, NJ: Princeton University Press.

Greenberg, J. H. (1978). Generalizations about numeral systems. In J. H. Greenberg (Ed.), Universals of human language (Vol. 3, pp. 249-295). Stanford, CA: Stanford University Press.

Haas, C. (1996). Writing technology: Studies on the materiality of literacy. New York: Routledge.

Henkelman, W. F. M., \& Folmer, M. L. (2016). Your tally is full! On wooden credit records in and after the Achaemenid Empire. In K. Kleber \& R. Pirngruber (Eds.), Silver, money, and credit: A tribute to Robartus J. van der Spek on the occasion of his $65^{\text {th }}$ birthday (pp. 133-239). Leiden, The Netherlands: Nederlands Instituut voor het Nabije Oosten.

Høyrup, J. (1994). In measure, number, and weight: Studies in mathematics and culture. Albany, NY: State University of New York Press.

Hutchins, E. (1995). Cognition in the wild. Cambridge, MA: MIT Press.

Hutchins, E. (2005). Material anchors for conceptual blends. Journal of Pragmatics, 37(10), 1555-1577.

Hutto, D. D., \& Myin, E. (2013). Radicalizing enactivism: Basic minds without content. Cambridge, MA: MIT Press.

Ifrah, G. (1981). The universal history of computing: From the abacus to the quantum computer. (R. Laffont, Trans.). New York: John Wiley \& Sons.

Ifrah, G. (2000). The universal history of numbers: From prehistory to the invention of the computer. (D. Bellos, E. F. Harding, I. Monk, \& S. Wood, Trans.). New York: John Wiley \& Sons.

Lambert, W. G. (1969). Review, O. R. Gurney and P. Hulin, The Sultantepe tablets II. Journal of Semitic Studies, 14(2), 242-247.

MacGinnis, J., Monroe, M. W., Wicke, D., \& Matney, T. (2014). Artefacts of cognition: The use of clay tokens in a Neo-Assyrian provincial administration. Cambridge Archaeological Journal, 24(2), 289-306.

Malafouris, L. (2010). Grasping the concept of number: How did the sapient mind move beyond approximation? In C. Renfrew \& I. Morley (Eds.), The archaeology of measurement: Comprehending heaven, earth and time in ancient societies (pp. 35-42). Cambridge: Cambridge University Press.

Malafouris, L. (2013). How things shape the mind: A theory of material engagement. Cambridge, MA: MIT Press. 
McCandliss, B. D., Cohen, L., \& Dehaene, S. (2003). The visual word form area: Expertise for reading in the fusiform gyrus. Trends in Cognitive Sciences, 7(7), 293-299.

Menninger, K. (1992). Number words and number symbols: A cultural history of numbers. (P. Broneer, Trans.). New York: Dover Publications.

Miller, H. (1980). Money and how it gets that way. Challenge: The Magazine of Economic Affairs, 23(1), 3-5.

Moore, A. M. T. (2000). Stone and other artifacts. In A. M. T. Moore, G. C. Hillman, \& A. J. Legge (Eds.), Village on the Euphrates: From foraging to farming at Abu Hureyra (pp. 165-186). Oxford: Oxford University Press.

Moscati, M. F. (1832). History and conversion of an anti-phrenologist. The Lancet, 1(480), 213-216.

Nakamura, K., Kuo, W.-J., Pegado, F., Cohen, L., Tzeng, O. J.-L., \& Dehaene, S. (2012). Universal brain systems for recognizing word shapes and handwriting gestures during reading. Proceedings of the National Academy of Sciences of the United States of America, 109(50), 20762-20767.

Nissen, H. J., Damerow, P., \& Englund, R. K. (1993). Archaic bookkeeping: Early writing and techniques of economic administration in the ancient Near East. (P. Larsen, Trans.). Chicago, IL: University of Chicago Press.

Núñez, R. E. (2017). Is there really an evolved capacity for number? Trends in Cognitive Sciences, 21(6), 409-424.

Overmann, K. A. (2014). Finger-counting in the Upper Palaeolithic. Rock Art Research, 31(1), 63-80.

Overmann, K. A. (2015). Numerosity structures the expression of quantity in lexical numbers and grammatical number. Current Anthropology, 56(5), 638-653.

Overmann, K. A. (2016a). Beyond writing: The development of literacy in the Ancient Near East. Cambridge Archaeological Journal, 26(2), 285-303.

Overmann, K. A. (2016b). Materiality in numerical cognition: Material Engagement Theory and the counting technologies of the Ancient Near East. Doctoral thesis, University of Oxford, Oxford.

Overmann, K. A. (2016c). Number concepts are constructed through material engagement: A reply to Sutliff, Read, and Everett. Current Anthropology, 57(3), 352-356.

Overmann, K. A. (2016d). The role of materiality in numerical cognition. Quaternary International, 405, 42-51.

Parthemore, J. (2013). The Unified Conceptual Space Theory: An enactive theory of concepts. Adaptive Behavior, 21(3), 168-177.

Pegado, F., Nakamura, K., \& Hannagan, T. (2014). How does literacy break mirror invariance in the visual system? Frontiers in Psychology, 5, 1-5.

Plato. (1892). Philebus. In B. Jowett (Trans.), The Dialogues of Plato: Parmenides, Theaetetus, Sophist, Statesman, Philebus ( $3^{\text {rd }}$ ed., Vol. 4). Oxford: Oxford University Press.

Reese, D. S. (2002). On the incised cattle scapulae from the East Mediterranean and Near East. Bonner Zoologische Beitrage, 50, 183-198.

Roux, F.-E., Boetto, S., Sacko, O., Chollet, F., \& Trémoulet, M. (2003). Writing, calculating, and finger recognition in the region of the angular gyrus: A cortical stimulation study of Gerstmann syndrome. Journal of Neurosurgery, 99(4), 716-727.

Russell, B. (1910). The theory of logical types. In D. Lackey (Ed.), Essays in analysis (pp. 215-252). New York: George Braziller.

Russell, B. (1920). Introduction to mathematical philosophy ( $2^{\text {nd }}$ ed.). London: George Allen \& Unwin. 
Saxe, G. B. (2012). Cultural development of mathematical ideas. Cambridge: Cambridge University Press.

Schmandt-Besserat, D. (1992). Before writing: From counting to cuneiform (2 vols). Austin, TX: University of Texas Press.

Semitic Roots. (2017). American Heritage Dictionary of the English Language (5 ${ }^{\text {th }}$ ed.). Boston: Houghton Mifflin Harcourt.

Shendge, M. J. (1983). The use of seals and the invention of writing. Journal of the Economic and Social History of the Orient, 26(2), 113-136.

Stewart, J. (2014). An enquiry concerning the nature of conceptual categories: A case-study on the social dimension of human cognition. Frontiers in Psychology, 5, 1-13.

Tixier, J. (1974). Poinçon décoré du Paléolithique Supérieur à Ksar’Aqil (Liban). Paléorient, 2, 187-192.

Tovino, S. A. (2007). Imaging body structure and mapping brain function: A historical approach. American Journal of Law and Medicine, 33(2\&3), 193-228.

Whittaker, G. (2002). Linguistic anthropology and the study of emesal as (a) women's language. In S. Parpola \& R. M. Whiting (Eds.), Sex and gender in the Ancient Near East: Proceedings of the 47 ${ }^{\text {th }}$ Rencontre Assyriologique Internationale, Helsinki, July 2-6, 2001 (Part II, pp. 633-644). Helsinki: The Neo-Assyrian Text Corpus Project.

Wilcke, C. (2005). ED Lú a und die Sprache(n) der archaischen Texte. In W. H. van Soldt (Ed.), Ethnicity in ancient Mesopotamia: Papers read at the $48^{\text {th }}$ Recontre Assyriologique International, Leiden, 14 July 2002 (pp. 430-445). Leiden, The Netherlands: Netherlands Institute.

Zahidi, K., \& Myin, E. (2016). Radically enactive numerical cognition. In G. Etzelmüller \& C. Tewes (Eds.), Embodiment in evolution and culture (pp. 57-71). Tübingen: Mohr-Siebich.

Zimansky, P. (1993). Review of Denise Schmandt-Besserat's Before writing, Volumes I and II. Journal of Field Archaeology, 20(4), 513-517. 